\title{
Identification of Ethical and Medicolegal Problems in the Care of Patients in the Intensive Care Unit
}

\author{
Taufik Suryadi ${ }^{1}$, Kulsum $^{2}$ \\ ${ }^{1}$ Department of Forensic Medicine and Medicolegal, Universitas Syiah Kuala Banda Aceh, Indonesia \\ 2Department of Anesthesiology, Faculty of Medicine, Universitas Syiah Kuala Banda Aceh, Indonesia \\ E-mail: taufiksuryadi@unsyiah.ac.id
}

\begin{abstract}
:
Intensive care is an important part of a hospital that serves patients with critical illness conditions and requires continuous medical supervision and support. The complexity of the problems related to intensive care results in ethical and medicolegal problems. Some of the ethical and medicolegal problems identified can be in the form of priority problems for patients entering and leaving the intensive care room, facility limitations, treatment is useless, terminal state, directive advances, do not resuscitate, brain stem death, euthanasia, and micro-ethical problems that arise directly during patient care which can cause a bad experience for patients and reduce the quality of service. Problem solving can be done by applying clinical ethics, basic principles of bioethics and medicolegal as well as effective communication. Doctors who work in intensive care installations must have the ability to determine patient priorities, be able to communicate well with patients and / or their families, and be able to provide end-of-life care based on basic principles of bioethics. This capability will lead to good and complete medical services.
\end{abstract}

Keywords:

ethics; intensive care; medicolegal; problem identification

\section{Introduction}

Intensive Care Unit (ICU) is an important part of the hospital that is used for patients with illnesses and injuries who experience a critical period. Patients who are treated at the ICU need continuous monitoring and support from the professional staff who has an expertise and high medical skills, and sophisticated medical equipment is also needed. Intensive care is expensive (high cost) so quality control and cost control in the form of effectiveness of treatment, length of stay and levels of morbidity and mortality must be considered (Marshal et al., 2017; Marik, 2015). Special consideration in determining who can be treated in the ICU becomes a separate polemic for both doctors, nurses, patients, and patients' families. In the United States it was noted that the mortality of patients in the ICU increased from 1994 to 2007 which from 18\% to $46 \%$. An ICU doctor must be able to determine patients who have the potential to be saved. Patient management decisions in the ICU can be decided by the patient if the patient has the capacity to decide and if not, can be represented by the family and if the patient and family cannot decide, then the doctor must be able to decide what to do with the patient. Therefore, a doctor in the ICU must be able to determine who can be treated, management and end of treatment to patients in the ICU according to medical indications based on ethical considerations (Zimmerman et al., 2013; Richardson \& Vizcaychipi, 2014).

Talking about ethics and medico-legal is inseparable from the current development of bioethics. Bioethics has developed as a new applied and disciplined discipline in the biomedical field since the 20th century. The principles of beneficence, non-maleficence, respect for autonomy and Justice are medical ethical principles that form the basic rules. The 
term macro-ethics and micro-ethics is a new term in the world of bioethics. Macro-ethics refers to problems that refer to ethical issues related to the allocation, ability and management of health resources. Micro-ethics includes a component of the interaction process that occurs between doctors and patients which includes history taking, physical examination, selection of therapies and decisions. Components in micro-ethics often cause ethical problems that give patients a bad experience and reduce the quality of service. Micro-ethic problems can be avoided by clinical ethics services. This article will discuss ethical and medicolegal issues in ICU service and the importance of clinical ethics services, so that they can be taken into consideration in making decisions while treating patients in ICU (Henky, 2018; Mandal et al., 2015).

\section{Review of Literatures}

\subsection{Problem Ethics in Determination of Patients Entering the ICU}

Determination of patients in and out of the ICU is not always a medical decision, it could be non-medical aspects such as pressure from the manager or the patient becomes one of the important roles in the decision making process. Decisions on intensive care must be made quickly when the acute situation and the high emotional situation experienced by the patient's family and patients can trigger ethical and medicolegal problems in the ICU. Family emotional factors can make it difficult to make objective decisions in determining the entry and exit of patients in the ICU (Tallgren et al., 2005; Ersoy et al., 2010).

The research conducted by Oerlemans et al, found that the problem in determining the admission of patients to the ICU was due to delays or confusion in determining the admission of patients due to the limited number of beds, the patient needed ICU care but had to be transferred to another hospital due to the full number of beds, differences of opinion about the initial management of patients in the ICU by doctors and nurses, decision making in an inaccurate state and incomplete information due to patients coming in critical condition. The problems that occur in the ICU are divided into 2 categories, namely ethical issues due to the number of beds and therapy. Ethical issues related to the number of beds arises from thinking about the benefits and risks that will be received by patients if treated in the ICU or the presence of other patients who have a better prognosis. Ethical problems due to therapy arise due to problematics in determining initial and final therapies that are weighed in terms of risks and benefits to patients (Oerlemans et al., 2015).

Critical patient care is a treatment that is limited and high cost. The availability of beds in ICU which is also limited becomes a big problem both in hospitals in developed and developing countries. This problem becomes a complex and challenging thing. In 2008, critical patient care in the United States was estimated to require a budget of 121 billion dollars to 263 billion dollars. This causes a very heavy burden on the country so that priority mechanisms are needed in determining patients who receive critical care in the ICU (Nates et al., 2015).

The priority mechanism for patients entering the ICU is very much needed if the facilities and infrastructure of an ICU in a hospital are limited and an ICU head is responsible for this. If the patient's need for an ICU exceeds the number of beds provided, then an ICU head must determine based on the priority of the medical conditions of the patient to be treated at the ICU. The procedure for implementing this policy must be explained in detail as shown in table 1 (Indonesia Law, 2010; Nates et al., 2015). 
Table 1. The priority of patients entering ICU

\begin{tabular}{cll}
\hline Priority & \multicolumn{1}{c}{ Case examples } \\
\hline I & 1. & \multicolumn{1}{c}{ Patients post cardiothoracic surgery } \\
& 2. Severe sepsis \\
& 3. Life-threatening acid-base balance and electrolytes \\
\hline II & 1. Patients suffering from basic heart-lung disease \\
& 2. Acute and severe kidney failure \\
& 3. Patients who have undergone major surgery \\
\hline III & 1. Patients with metastatic malignancies with complications of infection \\
& 2. Pericardial tamponade \\
& 3. Airway obstruction \\
& 4. Patients with heart disease and terminal lung disease accompanied by \\
IV & Patients who have metastasis and do not want to be intubated or resuscitated. \\
\hline V & Patients who experience irreversible processes due to cancer that has undergone \\
& metastasis and not done chemotherapy or radiotherapy
\end{tabular}

Patients who need intensive therapy (priority 1) take precedence over patients who only need intensive monitoring (priority 3 ) in the case of hospitals with limited ICU numbers. An objective assessment of the weight and prognosis of a disease is used as a basis in considering the priority of patients who enter the ICU. 8 Patients with priority 5 are patients who are advised to receive palliative therapy. These patients include patients with terminal disease who will not be able to recover, for example patients who experience an irreversible process due to cancer that has undergone metastasis and not done chemotherapy or radiotherapy (Kariadi, 2013).

\subsection{Ethical Problems When a Patient Leaves the ICU}

Ethical problems when patients leave ICU can also arise. Based on the research of Oerlemans et al, found ethical problems in the form of the end of the indicative period of treatment given, differences of opinion about the cessation of management in the ICU, the patient returned to stability after the termination of life assistance therapy and the patient was stable during administration and treatment at the ICU. Ethical issues when determining patients to leave ICU are not optimal or when patients are not yet discharged from ICU, this problem arises due to "overestimates" from the ICU on the ability of the room to receive patients after treatment in the ICU (Oerlemans et al., 2015).

\subsection{Limitation and Termination of Life Support at the ICU}

Intensive Care Unit (ICU) is intended for patients suffering from acute illness, injury or complications that are life threatening or potentially life threatening with the prognosis of dubia which is expected to be reversible. In patients who are incurable due to a disease (terminal state), termination or postponement of life support therapy (Kevin et al., 2018). The decision was made by considering the transition of intensive care to palliative care. The action is expected to occur without conflict, mutual understanding and agreement of the patient, the family representing the patient and the team that provides health services. In health services in Indonesia, policies regarding terminal patient conditions and medical measures that have been in vain are determined by the Director or Head of the Hospital (Indonesian Law, 2014).

The patient's family can ask the doctor to discontinue or postpone life support therapy or ask to assess the patient's condition for termination or postponement of life support therapy. Family requests for termination or postponement of life assistance therapy are regulated in article 15 of the Regulation of the Minister of Health of the Republic of Indonesia 
Number 37 of 2014 concerning Determination of Death and Utilization of Donor Organs. If there is a mismatch between the request of the family and the recommendation of the team appointed by the medical committee or ethics committee, while the family still requests the termination or postponement of life assistance therapy, legal responsibility rests with the family (Indonesian Law, 2014).

\subsection{Futility of Treatment}

Medical decision making must be based on the benefits that can be felt by the patient. If the doctor feels that the therapy given is no longer useful, then it is said to be futile. Morally, a doctor must explain to patients and their families that the therapy given is no longer useful, the decision making must be based on the best scientific considerations (Pozgar, 2005). Respect for the dignity of the patient (patient autonomy) in this condition the patient and his family must be done by a doctor. The doctor must provide relevant information to the patient's family related to the patient's illness (Levin \& Sprung, 2005). The doctor must ensure that the patient and his family understand the latest condition of the patient (Aeckermann, 2000). The most important thing that needs to be explained by doctors is when actions withholding life support and withdrawing life support are carried out when a medical action has changed from ordinary to extraordinary (Malik, 2013).

In making the decision to withholding and withdrawing life support in critical care patients, doctors must be very careful because comprehensive consideration is needed related to medical, ethical and medicolegal aspects. In addition to the reason for the patient's condition being medically in an incurable state due to his illness (terminal state), it can also be done if therapy or medical treatment is futile (Kusmaryanto, 2012).

\subsection{Determination of Brain Stem Death}

Doctors have an important role in determining the death status of patients who end of life is basic to provide appropriate action, accompany and provide patient care shortly before death (Queenland, 2018). Medicolegal death determinations in Indonesia are regulated through Minister of Health Regulation of the Republic of Indonesia Number 37 of 2014 concerning Determination of Death and Utilization of Donor Organs (Indonesian Law, 2014). Determination of a person's death can be done using clinical death diagnosis criteria or brain stem death death diagnosis criteria. Determination of death made using a diagnosis of brain stem death must be done at the ICU (Indonesia law, 2014).

The diagnosis of brain stem death largely determines the continuation of therapy the patient receives. To avoid futile medical measures, after diagnosis of brainstem death, all lifesupport therapy must be stopped. However, if the patient is an organ donor, life support therapy can be continued until the needed organs are removed. Before taking action to stop life assistance, informed consent must be made to the patient's family or those representing the patient (Indonesian Law, 2014; Queenland, 2018).

Determination of someone dead brain stem can only be done by three competent doctors in which must involve anesthetists and neurologists with the provisions of the examination carried out independently and separately. In the case of determining brain stem death by a prospective organ donor, the doctor conducting the diagnosis must not be a doctor involved in the organ transplantation act (Indonesian Law, 2010). Based on Article 10 paragraph 2 of the Regulation of the Minister of Health of the Republic of Indonesia Number 37 of 2014 concerning Determination of Death and Utilization of Donor Organs, the requirements that must be fulfilled for examination of brain stem death include: a.) There are preconditions in the form of coma and apnea caused by structural brain damage irreversible 
due to disorders that have the potential to cause brain stem death; and b.) There is no reversible cause of coma and stopping breathing due to drugs, intoxication, metabolic disorders and hypothermia. The procedure for examining brain stem death is carried out by ascertaining brain stem reflex was not found and ensuring a state of stopping breathing in accordance with what is explained in Article 11 of the Republic of Indonesia's Minister of Health Regulation No. 37 of 2014 concerning Determination of Death and Utilization of Donor Organs (Indonesian Law, 2014).

\subsection{Passive Euthanasia}

The discussion regarding euthanasia begins with question (1) what conditions does euthanasia occur? This is a question that must be answered so that there is no confusion because the division of euthanasia in some literature is rather confusing. The basic concept of euthanasia in principle if it meets three components, namely methods, intentions and motives. These three things must apply together, if one does not exist then it is not euthanasia. In this context what is meant by the method is to do or not do an action, the intention is to do or not do an action aiming that the patient dies, while the motive is out of compassion to relieve suffering. This review is slightly different from some other reviews that are often found in several libraries (Kusmaryanto, 2012).

The second question, is the act of euthanasia ethical or not?. Medical ethics generally allows passive euthanasia in the sense that patients are allowed to undergo their natural death (letting die naturally) without providing extraordinary actions or stopping extraordinary actions that prolong life, while still providing measures / treatments to control pain and provide patient comfort. Life-sustaining treatments alone are defined as any action intended to prolong life without changing the medical background (Aboudreau \& Somerville, 2013).

\subsection{Advance Directive}

In ICU care, if it is known that there is no indication of medical treatment for patients, so patients are planned for palliative care, doctors and nurses and the entire team can receive messages or statements of patients (advanced directive) related to their wishes or hopes or whether medical treatment may be needed on him if something happens when his competence decreases, for example coma (Pozgar, 2005). However, it is important to note that there are several conditions that must be met in accepting this advanced directive including: the condition of the patient when making advanced directive must be competent, there should be no coercion or pressure on the patient when the patient rejects an action, the patient can make explicit about the action may or may not be done, or can also appoint representatives who can make decisions when the patient is incompetent (Jordens et al., 2005). Written advanced directive statements are included in the medical record file as the main guide if palliative care is needed later.

\subsection{Do Not Resuscitation}

In treatment at the ICU many patients and their families ask not to be resuscitated if the patient's condition worsens. This often becomes an ethical dilemma for doctors and nurses. There is a need for regulation from the hospital about making decisions about whether or not to do cardiac pulmonary resuscitation (Do Not Resuscitation-DNR) at the request of patients and their families (Wheatley et al., 2015). DNR decisions can be made by competent patients and their families after discussions with the ICU team. Ethically the right to selfdetermination is the patient, in this case the patient must be competent so that he has the right to do or does not want resuscitation (DNR), the most important thing is when making a decision for DNR the patient must get adequate information. Decision making can be given in writing in the form of a message (advanced directive) or in informed consent before the 
patient loses his competence or the patient can give a decision to his family for DNR that has been ordered in advanced written directive (Jordens et al., 2005).

Ethical principles carried out at DNR also refer to the basic rules of bioethics (Beauchamp and Childress, 2013), namely the four basic principles of autonomy, beneficence, non-maleficence and justice, and according to clinical ethical considerations, namely medical indications, patient preferences, quality of life and contextual picture. i.e. if the patient is in a terminal stage (medical indications are gone) and resuscitation is known to not cure (no benefit anymore) or improve his quality of life based on scientific evidence at the time, the ICU team can make a decision not to resuscitate in accordance with clinical guidelines in this field (Beauchamp and Childress, 2013; Jonsen et al., 2010).

\section{Discussion}

\subsection{Clinical Ethics Services at ICU}

Decision making in care at the ICU is not only decided based on clinical aspects. Decision making in care at the ICU must also consider ethical and medicolegal aspects so clinical ethics services are needed. Clinical ethics services can be defined as providing advice and support for ethical issues arising from clinical practice and patient care in health care facilities, in this paper health services in the ICU. In general there are several models of clinical ethics services, for example emergency and non-emergency; authoritarian and mediation; clinical ethics committee and independent or mixed ethics consultant (Henky, 2018; Suryadi, 2017).

The main goal of clinical ethics services is to improve the quality of care and healing of patients. The most important benefit of clinical ethics services is to prevent lawsuits against medical service providers during conflicts between doctors and patients. Among these manifestations is the compilation of general procedural guidelines and standards to maximize communication and minimize conflicts that can arise in patient care, which in turn can reduce the potential risk of lawsuits on the part of recipients of health services. As a precautionary measure, the clinical ethics committee can prepare standard clinical ethics guidelines in the form of approval procedures for medical action, statements in advance or wills, decision making by the patient's representative, orders not to do resuscitation, determination of medical futility, initial related problem solving and end of life and other problems that have the potential to cause lawsuits so as to improve the quality of medical services according to the main objectives of clinical ethics services (Henky, 2018; Suryadi, 2017).

A well-organized clinical ethics service is expected to provide maximum benefits for patients in the delivery of health services and prevent the occurrence of medical malpractice. Intensive Care Unit is one part of the hospital that provides special medical services that are very vulnerable to conflicts between patients and health care providers. The delivery of clinical ethics services at the ICU aims to minimize the risk of lawsuits and the costs of medical malpractice in the delivery of health services (Henky, 2018; Kevin et al., 2018; Suryadi, 2017).

\subsection{Application of Basic Principles of Bioethics}

In medical science, known basic principles of bioethics which underlie clinical ethics services. These principles are divided into four basic rules and four derived rules. The four basic rules referred to are: (1) beneficence (benefits) (2) non-maleficence (not harming or hurting others) (3) respect for autonomy (respecting the freedom or wishes of patients), and (4) justice (fair). Whereas the four derived rules consist of: 1) veracity (honesty) (2) privacy (the patient's right to control access to information about himself) (3) confidentiality, and (4) 
fidelity (loyalty, keeping promises / contracts, and prioritizing patient interests). (Henky, 2018; Kevin et al., 2018; Suryadi, 2017).

\subsection{Medicolegal Application}

Medicolegal is an interdisciplinary between medical science and law. The medicolegal problem is an ethical event or problem that has the potential to cause civil or criminal legal issues that have implications for hospitals and their employees that usually arise due to poor relations between patients and doctors (Hanafiah \& Amir, 2009). Based on the Decree of the Minister of Health of the Republic of Indonesia Number 1778 / MENKES / SK / XII / 2010 concerning the Implementation of Intensive Care Services (ICU) in hospitals, it states that, ICU is an independent part of the hospital and has special staff and equipment used for observation, treatment and therapy in patients suffering from diseases, injuries or lifethreatening complications with dubia prognosis. The ICU provides capabilities, facilities, infrastructure and special equipment to support vital functions by utilizing the skills of medical staff, nurses and other staff who are experienced in handling this situation (Indonesian law, 2010).

Life support therapy given at the ICU can be stopped or postponed at a certain time. The therapy that is stopped or postponed is only therapeutic and / or extra-ordinary treatment which includes treatment in the Intensive Care Unit, cardiac pulmonary resuscitation, control of dysrhythmias, tracheal intubation, mechanical ventilation, vasoactive drugs, parenteral nutrition, artificial organs, transplants, blood transfusions, invasive monitoring, and administration of antibiotics and other measures specified in medical service standards. Life support therapy that cannot be stopped or postponed includes oxygen, enteral nutrition and crystalloid fluids, but sometimes this can lead to ethical dilemmas (Braganza et al., 2017; Indonesian law, 2014).

Ethically and medically, patients who are given care in the ICU have the right to autonomy, including issues concerning the end of life. In this case, it is necessary to discuss the end of life care as early as possible. For patients who survive and recover from critical illness after being treated in the ICU, an opportunity can be given to discuss their expectations about future ICU acceptance. This will encourage discussion between patients and their families regarding the patient's wishes in the future. Sometimes patients may not want to be treated again if they experience an unhealthy or critical condition (Goodman et al., 1998; Frivold et al, 2018).

\subsection{Effective Communication}

Good communication between patients, patients' families and doctors is very important in ICU care. Poor communication can cause harm to patients. For example in patients who cannot make their own decisions, the patient's rights are represented by the family. In families who are too emotional to direct decisions toward death or interfere with the quality of life of patients who are clearly not in accordance with the wishes of patients. As another example, a doctor accidentally or intentionally makes decisions based on self rather than expected by the patient (Visser et al, 2014; Kon et al., 2017).

In terms of manpower, doctors and nurses working in the ICU experience heavy pressure in thinking about the patient's final life decision. This is caused by the perception of medical personnel who consider it inappropriate to talk about. Discussions between patients, family and medical personnel are needed in determining the management and end-of-life care of a patient in the ICU. In this case good communication is needed between the doctor and the patient or his family, so that the goals and desires of the patient and family are clear and do not interfere with the rights of the patients themselves (Visser et al, 2014; Kon et al., 2017). 


\section{Conclusion}

Ethics and medicolegal issues around intensive care need to be discussed continuously because intensive care is full of ethical and legal issues. Doctors and nurses who are in the ICU must have the ability to make medical decisions based on ethical considerations, in addition to good cognitive abilities and skills, ethical and humanist behavioral abilities are also required. The important role of doctors and nurses in determining the priority of patients both in and out of the ICU and good communication skills with patients or their families can prevent the occurrence of ethical and medicolegal issues, so that good and complete medical services are achieved.

\section{References}

Aboudreau, J.D. \& Somerville, M.A. 2013.Euthanasia is not Medical Treatment. British Medical Bulletin. 1-22.

Aeckermann, R.J. 2000. Withdrawal and Withholding life sustaining treatment. Am Fam Physician. 62(7): 1555-60.

Braganza, M.A., Glossop, A.J, \& Vora, V.A. 2017. Treatment Withdrawal and End of Life Care in The Intensive Care Unit. BJA Education.2017.17(12). 396-400.

Beauchamp, T.L., \& Childress, J.F.2013. Principles of biomedical ethics (7th ed). New York: Oxford University Press.

Ersoy, N., \& Akpinar, A. 2010.Turkish Nurses' Decision Making in the Distributin of Intensive Care Beds. Nurs Ethics.17:87-98.

Frivold, G., Slettebo, A., Heyland, D.K., \& Dale, B.2018. Family Members' Satisfaction with Care and Decision Making in Intensive Care Units and Post Stay Follow Up needs a Cross Sectional Survey Study. Nursing Open. 6-14.

Goodman, M.D., Tarnoff, M., \& Slotman, G.J. 1998. Effect of advance directives on the management of elderly critically ill patients. Crit Care Med.26(4):701.

Hanafiah, J., \& Amir, A. 2009. Etika Kedokteran dan Hukum Kesehatan. 2009. EGC. Jakarta. 47-61

Henky. 2018. Pelayanan Etika Klinis. Jurnal Etika Kedokteran Indonesia. 2(2):59-66.

Indonesian Law, 2010. Regulation of the Minister of Health of Republic of Indonesia Number 1778 / Menkes / SK / XII / 2010 concerning Guidelines for Organizing Intensive Care Unit Services in Hospitals. Jakarta.

Indonesian Law, 2014. Regulation of Minister of Health of Republic of Indonesia No. 37 of 2014 concerning Determination of Death and Utilization of Donor Organs. Jakarta.

Jonsen, A.R., Siegler, M., \& Winslade, W.J. 2010. Clinical Ethics a Practical Approach to ethical Decisions in Clinical Medicine.7th ed. The McGraw Hill Companies. New York.

Jordens, C., Little, M., Kerridge, I., \& McPhee, J. 2005. From Advance Directives to Advance Care Planning: Current Legal Status, Ethical Rationale and a New Research Agenda. Intern Med J. 35: 563-566.

Kariadi, D.R.D. 2013. Guidelines for Patient Criteria in and Out Intensive Care Rooms. RSUP Dr. Kariadi Semarang.

Kon, A.A., Davitson, J.E., Morrison, W., Danis, M., \& White, D.B. 2017. Shared Decision Making in Intensive Care Units: An American Collage of Critical Care Medicine and American Thoracic Society Policy Statement. Crit Care Med.1-27

Kevin, J.S., Amanda, L.R., \& Christopher, J.D. 2018. Witholding and Withdrawing Life Support: Difficult Decissions around Care at The End of Life. Can J Anaesth. 65: 913. 
Kusmaryanto, J.B. 2012. Ethical problem at the end of life. Center for Bioethics and Medical Humanities. Kursus Bioetika, Yogyakarta 16 - 20 April 2012.

Levin, P.D., \& Sprung, C.L. 2005. Withdrawal and Withholding life sustaining are not the same. Critical care. 9(3): 230-232.

Malik, M.M. 2013. Islamic perceptions of medication with special reference to ordinary and extraordinary means of medical treatment. Bangladesh Journal of Bioethics. 4(2): 2233.

Mandal, J., Dinoop, K.P., \& Parija, S.C.2015. Microethics in Medical Education and Practice. Tropical Parasitology. 5 (2):86-7.

Marik, P.E. 2015.Evidence Based Critical Care. New York. Springer.19-21.

Marshal, J., Bosco, L., Adhikari, N.K., Connolly, B., Diaz, J.V., Dorman, T., et al. 2017. What is An Intensive Care Unit? A Report of The Task Force of The World Federation of Societis of Intensive and Critical Care Medicine. Journal of Critical Care. 23:270-276.

Nates, J.L., Kleinpell, R., Goldner, J., Fowler, C.S., Miles, W.S., \& Sprung, C.L. 2016. ICU Admission, Discharge, and Triage Guidelines: A Framework to Enhance Clinical Operations, Development of Institutional Policies and Further Research. Critical Care Medicine. 1553-602.

Oerlemans, A.J., Sluisved, N.V., Leeuwen, E.S., Wollersheim, H., Dekkers, W.J., \& Zegers, M. 2015. Ethical Problems in Intensive Care Unit Admission and Discharge Decisions: a Qualitative Study Among Physician and Nurses in the Netherlands. BMC Medical Ethics.16(9): 1-10.

Queensland Health. 2018. End-of-Life Care: Guidelines for Decisions-making about Witholding and Withdrawing Life-sustainning Measures from Adults Patients. Australia: Queensland. 99-117.

Richardson, A.L., \& Vizcaychipi, M.P. 2014. Medicolegal Aspects of Treatment on The Intensive Care Unit. Elsevier. 37-40.

Suryadi, T. 2017. Aspek Bioetika-Medikolegal Penundaan Dan Penghentian Terapi Bantuan Hidup Pada Perawatan Kritis. Jurnal Kedokteran Syiah Kula. 17(1): 60-64.

Tallgren, M., Klepstand, P., Sakram, U., \& Hynninen, M. 2005. Ethical Issues in Intensive Care a Survey Among Scandinavian Intensive. Acta Anaesthesiol Scand.49:1092-1100.

Visser, M., Deliens, L., \& Houttekie, D. 2014. Physician Related Barriers to Communication and Patient and Family center decision Making Towards The End of Life in Intensive Care: a Systematic Review. Critical Care.18:1-19.

Wheatley, V.J., Smith, J.G., \& Finlay, N.G. 2015. Ethical Issues in Palliative Care. Medicine.

Zimmerman, J.E., Kramer, A.A., \& Knaus, W.A. 2013. Changes in Hospital Mortality for United States Intensive Care Unit Admissions from 1988 to 2012. BioMed Central.17(2):2-9.. 